\title{
EFICÁCIA DE UM SIMULADOR MULTIMÍDIA NO ENSINO DE TÉCNICAS BÁSICAS DE VIDEOCIRURGIA PARA ALUNOS DO CURSO DE GRADUAÇÃO EM MEDICINA
}

\author{
EFFICACY OF MULTIMEDIA SIMULATOR IN TEACHING BASIC SKILLS IN \\ VIDEOSURGICAL TECHNIQUES FOR UNDERGRADUATE STUDENTS OF MEDICINE
}

\author{
Eymard Francisco Brito de Oliveira, TCBC-MG'; João Luiz Moreira Coutinho Azevedo, ECBC-SP²; \\ Otávio Cansanção de Azevedo ${ }^{3}$
}

\begin{abstract}
RESUMO: Objetivo: Avaliar a eficácia de programa educacional informatizado, com recursos de multimídia, como instrumento de ensino para alunos do segundo ano do curso de graduação em Medicina. Método: Para este estudo prospectivo, duplo cego e randomizado foi desenvolvido um simulador multimídia de técnicas básicas de videocirurgia. Doze alunos selecionados foram aleatoriamente distribuídos em Grupo 1 (orientados a navegar individualmente no simulador) e Grupo 2 (levados a assistir a uma aula expositiva). Posteriormente, foram submetidos a avaliação objetiva com 10 questões práticas. Os alunos do Grupo 1 também avaliaram subjetivamente o programa. Resultados: No Grupo 1, 16,7\% dos alunos acertaram 8 procedimentos, 50,0\% acertaram 9 e $33.3 \%$ acertaram os 10 . No Grupo 2, 50,0\% dos alunos acertaram 9 procedimentos e 50,0\% acertaram os 10 procedimentos. Não houve diferença estatística entre os grupos (teste de Mann-Whitney; $\mathrm{p}=0,423$ ). Na análise subjetiva, 83,3\% concordaram que o programa foi de fácil uso, $83,4 \%$ acharam-no agradável e 50,0\% concordaram ter tido um feed-back imediato. Todos concordaram que o programa foi didático e afirmaram o desejo de ter programas assim para outros tópicos, mas metade discordou que programas como este já são suficientes para substituir o professor. Conclusão: O programa é eficaz na aprendizagem de técnicas básicas de vídeocirurgia para os alunos do segundo ano do curso de graduação em Medicina (Rev. Col. Bras. Cir. 2007; 34(4): 251-256).
\end{abstract}

Descritores: Educação médica; Tecnologia Educacional; Educação à distância; Ilustração Médica; Multimídia; Pneumoperitônio artificial; Laparoscopia.

\section{INTRODUÇÃO}

Há muitos séculos, o movimento de propulsão das civilizações é o desejo de adquirir conhecimentos e a vontade de transmiti-los. O ser humano conheceu muitas modalidades de divulgação de conhecimentos em sua história desde a transmissão direta da informação do mestre ao seu discípulo no convívio diário, até à época atual, com a revolução trazida pela escrita, a imprensa, o rádio, o cinema, a televisão, o vídeo cassete, a informática com a multimídia e a internet, entre tantos outros meios.

$\mathrm{Na}$ área médica, por exemplo, para o desenvolvimento da habilidade manual, requisito básico para o treinamento do cirurgião, um longo percurso vem sendo percorrido, desde o treinamento com animais até o ensino tutorial tendo como substrato o próprio homem, passando pela utilização de bo- necos e de imagens virtuais nos laboratórios simulados de cirurgia $^{1}$.

As técnicas operatórias atingem novo patamar, graças à revolução no campo da informática com desenvolvimento de programas multimídias e simuladores, que trazem consigo ilimitadas perspectivas. Não obstante, técnicas pedagógicas modernas voltadas para ensino da videocirurgia encontram-se em fase de experimentação, não se podendo, ainda, aquilatar-se o seu real valor.

Apesar de várias pesquisas indicarem que programas multimídia em comparação com aula teórica do tipo expositiva apresentam resultados semelhantes, quanto ao aspecto cognitivo, não pôde ser encontrado na literatura nenhum estudo desenvolvido sobre simuladores de vídeocirurgia utilizando um teste prático para avaliar o aprendizado.

1. Especialista em Cirurgia Experimental; Doutor em Educação; Pesquisador do Grupo de Vídeocirurgia - CNPq/UNIFESP.

2. Professor Adjunto Mestre e Doutor do Departamento de Cirurgia e Responsável pelo Setor de Videocirurgia da Disciplina de Técnica Operatória e Cirurgia Experimental (TOCE) da Universidade Federal de São Paulo (UNIFESP); Professor Orientador do Programa de Pós-Graduação em Cirurgia e Experimentação da UNIFESP; Ex-Professor Visitante da Universidade de Lyon, França; Líder do Grupo de Pesquisa em Videocirurgia do $\mathrm{CNPq} / \mathrm{UNIFESP}$.

3. Médico-Assistente do Serviço de Gastroenterologia Cirúrgica do Hospital do Servidor Público do Estado de São Paulo; Doutorando do Programa de Pós-Graduação em Cirurgia e Experimentação da Universidade Federal de São Paulo (UNIFESP); Pesquisador do Grupo de Videocirurgia do $\mathrm{CNPq} / \mathrm{UNIFESP}$

Recebido em 01/11/2006

Aceito para publicação em 05/01/2007

Conflito de interesses: nenhum

Fonte de financiamento: nenhuma

Trabalho desenvolvido no Setor de Vídeocirurgia da Disciplina de Técnica Operatória e Cirurgia Experimental da Universidade Federal de São Paulo (UNIFESP), e do Programa de Pós Graduação em Cirurgia e Experimentação - Grupo de Pesquisa em Vídeocirurgia da UNIFESP/CNPQ.

Tese de Doutorado de Eymard Francisco Brito de Oliveira Defendida e Aprovada no Programa de Doutorado em Educação da Universidade Vale do Rio Verde (UNINCOR) em outubro de 2005. 
Nesta pesquisa avaliou-se a eficácia de um simulador multimídia na aprendizagem de Técnicas Básicas de Videocirurgia, para alunos do segundo ano do curso de graduação em Medicina.

\section{MÉTODO}

O desenho deste estudo se caracterizou por ser prospectivo, duplo cego e randomizado. Foi confeccionado para esse estudo um simulador multimídia sobre Técnicas Básicas de Vídeocirurgia. Foram enfatizados aspectos elementares de uma sala cirúrgica com o material necessário para a execução de procedimentos vídeolaparoscópicos além de simular a técnica de pneumoperitônio com a Agulha de Veress. Esse Simulador encontra-se disponível no site: www.cirurgiaonline.med.br .

Definiu-se como amostra para o estudo o total de 12 alunos da segunda série do curso de Medicina da UNIFESP/ EPM. Estes alunos foram escolhidos porque não tiveram contato com o conteúdo de vídeocirurgia em sua grade curricular. O pequeno número da amostra se deu devido a característica da pesquisa por ter como critério de validação do simulador multimídia uma avaliação prática, o que inviabilizaria uma amostra maior.

Como critério de inclusão permitiu-se que qualquer aluno, de um universo de 30 alunos, do segundo ano do curso médico da instituição em rodízio na disciplina de técnica operatória e cirurgia experimental participasse da entrevista de seleção para o estudo.

Já como critérios de exclusão descartou-se a participação de alunos com experiência prévia em videocirurgia. Foram escolhidos aleatoriamente 12 alunos dos alunos aprovados na entrevista.

Os 12 alunos selecionados para o experimento foram distribuídos aleatoriamente, por sorteio, em dois grupos de seis alunos. Os alunos do Grupo I forma orientados para estudar o programa multimídia por 60 minutos, através de navegação individual em seis computadores da Disciplina de Técnica Operatória e Cirurgia Experimental da Escola Paulista de Medicina. Simultaneamente, os alunos do Grupo II, foram leva- dos para assistir uma aula com o mesmo conteúdo do programa multimídia, com duração de 60 minutos, na qual foi utilizado data show como recurso didático. Logo após essa etapa, os alunos foram levados ao centro cirúrgico da Disciplina de Técnica Operatória e Cirurgia Experimental da UNIFESP/EPM. Foram submetidos a uma avaliação prática com 10 questões sobre os assuntos estudados. (Tabela 1) para demonstrar conhecimentos básicos e práticos do equipamento de videocirurgia e executar as provas com a agulha de Veress puncionada no abdômen de um animal de experimentação que, para nosso estudo em videocirurgia foi escolhido um porco anestesiado previamente. Aprovado pela Comissão de Ética em Pesquisa da Universidade Vale do Rio Verde.

Posteriormente, foi solicitado aos alunos do Grupo I que procedessem a uma validação subjetiva do programa, através de um questionário com seis afirmativas baseado na escala de Likert, na qual deveriam responder se concordavam ou não com as respectivas afirmações (Tabela 2).

Os autores do programa multimídia não sabiam do conteúdo da aula teórica nem da prova. $\mathrm{O}$ professor que ministrou a aula teórica, não sabia do conteúdo do programa multimídia nem das questões da prova. O professor responsável pela prova, não sabia do conteúdo do programa multimídia nem da aula teórica.

Para a análise dos resultados da prova prática, aplicouse como método estatístico, o teste estatístico de Mann-Whitney, com o objetivo de comparar o Grupo 1 com o Grupo 2, em relação aos valores das notas atribuídas nas questões práticas.

\section{RESULTADOS}

A avaliação objetiva mostrou que no Grupo I, 16,7\% dos alunos acertaram oito procedimentos, 50,0\% acertaram nove procedimentos e $33,3 \%$ acertaram os 10 procedimentos, com média de 9,2 \pm 0,75 acertos e no Grupo II, 50,0\% dos alunos acertaram nove procedimentos e $50,0 \%$ acertaram os 10 procedimentos, com média de $9,5 \pm 0,55$ acertos.

Não foi encontrada diferença estatisticamente significante entre os grupos quanto ao número de acertos obtidos pelos alunos $(\mathrm{p}=0,423)$.

Tabela 1 - Questões da Prova Prática dos dois Grupos.

\begin{tabular}{|c|c|c|c|}
\hline Primeira & Identificar os equipamentos necessários a uma vídeo cirurgia & Certo & Errado \\
\hline Segunda & Identificar a Agulha de Veress na mesa de material cirúrgico & Certo & Errado \\
\hline Terceira & Descrever o local e o ângulo de punção da Agulha de Veress no abdome de um porco anestesiado & Certo & Errado \\
\hline Quarta & Realizar a manobra da Prova do Escoamento & Certo & Errado \\
\hline Quinta & Realizar as manobras da prova da Aspiração do conteúdo & Certo & Errado \\
\hline Sexta & Realizar as manobras da Infusão da Solução & Certo & Errado \\
\hline Sétima & Realizar as manobras da Prova de Recuperação da Solução Infundida & Certo & Errado \\
\hline Oitava & Realizar as manobras da prova de Gotejamento de Solução através da Agulha de Veress & Certo & Errado \\
\hline Nona & Ligar o insuflador e ajustar a pressão máxima & Certo & Errado \\
\hline Décima & Conectar a mangueira do insuflador à agulha e ajustar o fluxo de gás & Certo & Errado \\
\hline
\end{tabular}


Tabela 2 - Questionário de opinião de Likert.

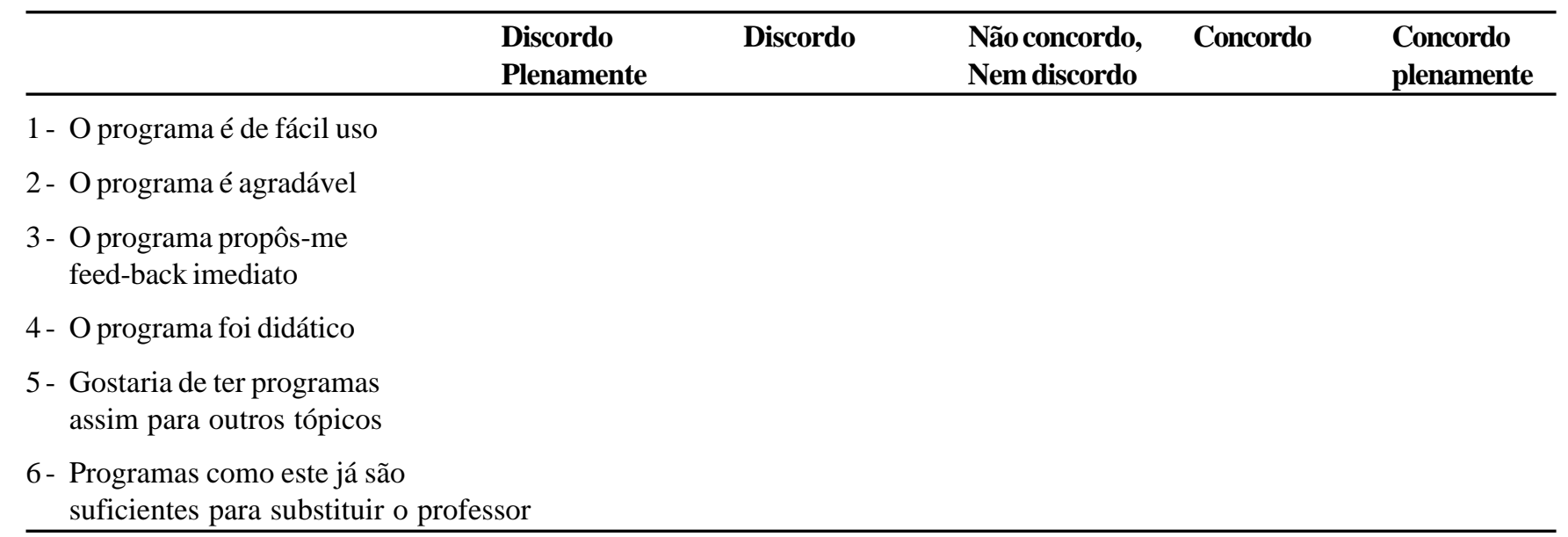

A avaliação subjetiva aplicada aos alunos do Grupo I mostrou que $83,3 \%$ dos alunos concordaram com a afirmativa de que o programa multimídia é de fácil uso. A maioria dos alunos $83,4 \%$, concordaram que o programa é agradável e $50,0 \%$ concordaram que o programa mostrou feed-back imediato; $100,0 \%$ dos alunos concordaram que o programa foi didático e que desejariam ter programas assim para outros tópicos e 50,0\% discordaram que programas como este já são suficientes para substituir o professor.

\section{DISCUSSÃO}

O objetivo desta pesquisa foi demonstrar que a técnica multimídia, com seus recursos agregados, pode ser um instrumento eficaz e útil para a aquisição de competências e habilidades na área da videocirurgia. Com este intuito, desenvolvemos um programa multimídia aplicado ao ensino de técnicas operatórias básicas em videocirurgia, mais precisamente apresentação do material básico para procedimentos videocirúrgicos, técnicas de punção e provas com Agulha de Veress. A escolha da técnica de punção abdominal com a Agulha de Veress no hipocôndrio esquerdo para realização de pneumoperitônio se deu devido aos riscos de acidentes fatais pela perfuração de grandes vasos e vísceras abdominais durante os procedimentos vídeocirúrgicos, sendo a preferida pelos autores 2 .

O ensino médico praticado no curso de graduação passa por importantes modificações. $\mathrm{O}$ modelo atual baseiase no binômio aula teórica/aula prática. O novo paradigma tende a alicerçar-se na resolução de problemas e no autoaprendizado $^{3}$. Neste contexto, o ensino baseado na informática e na utilização da multimídia é uma inovação que pode complementar a limitada educação tradicional oferecida aos estudantes de medicina ${ }^{4}$.

Existem quatro requisitos fundamentais para se justificar a adoção de qualquer novo sistema, tecnologia ou estratégia de ensino: rapidez na elaboração, menor dispêndio, maior facilidade e obtenção de melhores resultados ${ }^{5}$.

A tecnologia multimídia permite ao educador a economia de tempo na medida, que possibilita a introdução de novos textos, gráficos, áudios, animações e gravações em vídeo. Estes podem ser rapidamente trocados, reeditados ou apagados em poucas horas, o que não é possível em um ambiente não digital. Pode-se citar como exemplo a correção ou atualização de uma revista médica, que quando necessária, necessita de aguardar a próxima edição. Já para a reedição de um livro, são necessários alguns anos ${ }^{6}$.

Nos estágios iniciais, a adoção da multimídia no ensino médico mostra-se mais dispendiosa. Isto se relaciona diretamente ao método de confecção do novo sistema, em que são necessários gastos com hardware e com software. No entanto, à medida que a criação de novos programas multimídia dedicados à Medicina se populariza, os gastos diminuem de tal modo que a versão final, disponibilizada sob a forma de CD-ROM ou como página eletrônica da Internet custa até dez vezes menos do que a versão em papel ${ }^{7}$.

A utilização de um programa multimídia é fácil e simples. Desde que existam orientações iniciais mínimas (como navegar, como utilizar os botões para avanço, pausa ou retrocesso, como sair do programa), não se necessita de muita familiaridade com o computador ${ }^{8}$.

A utilização da multimídia para o ensino médico é, em tese, melhor do que os métodos tradicionais de ensino, porque a transmissão do conhecimento se torna mais eficiente $\mathrm{e}$ mais produtiva quando se utilizam imagens de alta qualidade, se adicionam som e movimento, se altera o conteúdo mais rapidamente e se reduzem os custos de produção ${ }^{5}$.

Outra diferença fundamental dos processos didáticos-instrucionais tradicionais (texto escrito e aula expositiva) em relação aos que utilizam a multimídia é que os últimos permitem que as diferenças individuais dos alunos sejam preservadas, já que é o estudante que impõe o ritmo e a ordem do aprendizado. A apresentação das informações não se faz de modo linear, pois o programa pode ter recursos que permitam examinar o material informativo em qualquer ordem, ou acessala de acordo com sua necessidade ${ }^{9}$.

O resultado é um aprendizado mais ativo, direto, através de uma melhor visualização e, conseqüentemente, de uma melhor compreensão do tópico estudado ${ }^{10}$. 
Além disso, a utilização da multimídia como método de aprendizado também parte do pressuposto de que se aprende mais rapidamente, compreende-se melhor e retém-se mais o conhecimento, quando nossos sentidos são estimulados de modo contínuo e em múltiplos níveis ${ }^{5}$.

A multimídia estimula continuamente o estudante, pois as narrações, as ilustrações e as animações mudam constantemente, enquanto que as pausas são freqüentes, fazendo que o aluno se mantenha mais atento. Todavia, em uma aula expositiva tradicional, os alunos mantêm-se alerta somente nos dez minutos iniciais. A partir daí, a tensão declina continuamente e só volta a crescer próximo ao encerramento ${ }^{11}$.

Estima-se em $20 \%$ a redução da carga-horária despendida em aulas expositivas com adoção da multimídia no ensino médico ${ }^{12}$. Além disso, as apresentações que incorporam meios visuais diversos, tais como os diapositivos de 35 $\mathrm{mm}$, as transparências e os gráficos coloridos, demonstraram se $43 \%$ mais eficazes na compreensão do assunto do que as apresentações que não utilizam estes meio 5 .

Validação, por definição, é o ato de se legitimar um fenômeno. Validar formalmente um programa multimídia como instrumento de ensino é importante para melhor se compreender o seu impacto na educação médica ${ }^{13}$.

A importância de nosso estudo é que ele se apoiou num desenho experimental rigoroso, com validação científica de sua eficiência. Não houve preocupação com o nível de familiaridade dos alunos com o computador, já que sabidamente isto não restringe ou impede o uso do aparelho, desde que o programa seja de fácil uso ${ }^{8}$.

Optou-se pela não aplicação de uma prova (pré-teste) antes do estudo (navegação versus aula), porque, mesmo sabendo-se que a aplicação do pré-teste não influi no resultado da prova aplicada após o estudo (pós-teste), também não influi no aprendizado final ${ }^{14}$.

A avaliação de um programa como instrumento de ensino pode ser dividida em dois âmbitos: o objetivo e o subjetivo. O primeiro, por exemplo, através da comparação de acertos e erros obtidos em um prova. O segundo, através das respostas a um questionário de opiniões sobre a eficácia do método em estudo ${ }^{14}$.

No presente estudo, avaliação objetiva constou da realização de uma prova com dez questões práticas, tendo como meta a verificação da aquisição de habilidades e competências referente ao tópico Técnicas Básicas de Videocirurgia. O Grupo 1 que se utilizou do programa multimídia obteve Média (dp) 9,2 (0,75) de acertos, enquanto que o Grupo 2, que assistiu à aula expositiva obteve Média (dp) 9,5 (0,55) de acertos. A diferença entre os grupos não foi estatisticamente significante.

No presente estudo, utilizamos a escala com cinco pontos, em que o estudante, em cada afirmativa, poderia discordar completamente, discordar, manter-se neutro, concordar ou concordar completamente. A partir de seis afirmações criadas pelo autor sobre a aceitação do programa, os alunos puderam mencionar o seu grau de concordância com elas. $\mathrm{O}$ objetivo desta fase foi analisar duas dúvidas educacionais: os alunos consideram satisfatório o emprego do programa multimídia para o ensino médico? (afirmativas de 1 a 5): na concepção deles, chegou o momento de o computador substituir o professor no ensino da Medicina? (afirmativa 6).

Em relação à primeira dúvida, pode-se afirmar que, de modo global, os alunos aceitaram o programa multimídia de modo satisfatório: 83,3\% concordaram com que o programa havia sido de fácil uso; $83,4 \%$ acharam agradável; $50,0 \%$ alegaram ter havido um retorno imediato (feedback) de conhecimento; $100,0 \%$ consideraram o programa didático e gostariam de ter programas como este para outros tópicos da Medicina.

No tocante à segunda dúvida a metade $(50,0 \%)$ dos alunos discordaram da afirmação de que programas como este já são suficientes para substituir o professor.

Os dados mostram que a utilização da multimídia no ensino da medicina faz com que os alunos tenham o mesmo desempenho e, por conseguinte, infere-se que obtenham os mesmos níveis de cognição, quando comparados à aula expositiva tradicional. O mesmo foi verificado em estudos realizados com a utilização de um programa multimídia sobre: Urologia ${ }^{15,16}$, Neuroanatomia ${ }^{17}$ e Técnica Cirúrgica ${ }^{18}$. Assim, a maioria dos alunos concorda com que o programa é agradável, didático, de fácil uso, além de proporcionar uma memorização imediata. Resultados semelhantes foram verificados em estudos que empregaram a multimídia para ensinar Riscos Ambientais e Ocupacionais para a Saúde Humana ${ }^{19} \mathrm{e}$ Fisiologia Humana ${ }^{8-12}$. No Entanto, os alunos não gostariam de ver os professores afastados do processo de aprendizado. No estudo de Riscos Ambientais e Ocupacionais para a Saúde Humana, o principal motivo alegado pelos alunos para explicar este sentimento foi a perda do "contato humano", fenômeno impossível de ser verificado com o uso do computador ${ }^{19}$.

Na avaliação subjetiva, os alunos do Grupo I discordaram que programas interativos multimídia como o apresentado a eles são suficientes para substituir o professor. Este tem como trabalho primordial não só ensinar, mas educar; isto é, formar, dar exemplo, servir de parâmetro a novas gerações, sendo um tutor do seu aluno; ofício muito maior que a de um simples repetidor de informações adquiridas, já que este tipo de trabalho poderá ser substituído, com vantagens, por novos métodos de aprendizagem, dentre eles os simuladores multimídia que, com certeza, serão incorporados em um futuro próximo ao ensino da medicina.

No nosso estudo não foi possível averiguar a retenção de conhecimento proporcionado pelo programa multimídia. Isto só seria possível se após determinado período de tempo, os mesmos alunos fossem convocados e submetidos a mesma prova ou prova semelhante com questões similares às do estudo original. Correr-se-ia o risco de eventual contaminação do resultado, caso algum estudante conduzisse estudos adicionais em técnicas básicas de vídeocirurgia através de livros textos ou de quaisquer outros métodos de ensino.

Esta nova fase do estudo também poderia esclarecer outro ponto duvidoso, ou seja, qual a taxa de alunos que realizaria pesquisas adicionais sobre o tema após determinado período de tempo. Para este fim, seria necessário disponibilizar o programa multimídia para o uso domiciliar (por exemplo, sob a forma de CD-ROM). Esta informação seria importante, pois em um estudo com um programa computacional 
para o ensino de câncer, realizado no ano de 1989, esta taxa foi de apenas $20 \%{ }^{20}$.

A mudança de paradigma ocorre lentamente. $\mathrm{O}$ nosso estudo mostrou que a multimídia é um método útil para o ensino da Medicina e que, em termos de eficácia, é similar ao atual, baseado em giz, retroprojetor, data-show e livro-texto, ambientado em uma sala repleta de alunos desmotivados. Prevê-se, para o futuro, a transferência de boa parte do ensino médico para o domicílio do aluno, onde ele poderá estudar do seu próprio modo ${ }^{3}$. A maneira pela qual isto será possível está em estudo nas grandes universidades mundiais. Vale lembrar que, com a tecnologia atualmente existente, a maior parte da informação científica necessária para o ensino e prática da medicina está disponível na ponta dos dedos, através dos teclados dos computadores ${ }^{21}$.

Além disso, páginas eletrônicas na Internet, relevantes para o ensino das disciplinas médica, proliferam rapidamente. Inovações, como a Inteligência Artifical, o Hospital Virtual, a Telemedicina e a Internet 2 que liga grandes universidades e centros de pesquisa de uma forma mais rápida, permitem a simulação de casos clínico-cirúrgicos, assim como a transmissão mais nítida e em tempo real dos textos, animações, áudio e vídeo ${ }^{22}$.
O professor manter-se-á em seu posto. Os alunos, tal qual o nosso estudo também demonstrou, apesar de amplamente favoráveis à utilização do computador para o ensino da medicina, não desejam perder o "contato humano", afetivo, proporcionado pelo mestre ${ }^{23}$. Mas o papel deste deverá ser revisado, pois, sendo o elo humano da nova corrente, provavelmente atuará como tutor ou guia, permanecendo disponível para as eventuais consultas assim como para sanar as dúvidas dos alunos.

Finalmente, a postura dos estudantes frente ao novo paradigma também deverá ser mudada. As novas tecnologias educacionais provenientes da informática aprimorarão e fortalecerão a capacidade de aprendizado ${ }^{24}$. Por outro lado, haverá um montante sempre crescente de novos conhecimentos advindos da pesquisa. Apesar da tutoria do professor, muitas vezes caberá ao próprio aluno, no regime de auto-aprendizado que o computador proporciona, saber pesquisar e selecionar as novas informações, separando as úteis das inúteis.

O programa educacional de computador, com recursos multimídia, mostrou-se eficaz na aprendizagem de técnicas básicas de vídeocirurgia para os alunos do segundo ano do curso de graduação em Medicina e que os estudantes concordam que programas como estes não são suficientes para substituir o professor.

\begin{abstract}
Backgroud: The search for new pedagogical tools is unremitting in every phase of the history of Mankind. The Information Technology has come to join the collection of resources that educators can rely on. Methods: The purpose of this task was to develop a computer educational program, with multimedia resources, and review its efficiency as a teaching aidfor students in their second year of Medical School. This was a double-blind, randomized, prospective trial. An educational interactive multimedia program on Basic Videosurgery Techniques was developed for this research. Twelve students were selected to take part in the experiment and randomly divided into two groups of six. Group I students were instructed to individually use the multimedia simulator for 60 minutes, while Group II students were invited to watch a one-hour theoretical class with Datashow as a teaching aid. Group I were also asked to carry out, through a questionnaire, a subjective validation of the program. Results: he Mann-Whitney test was used for the statistics analyses. 16.7\% of the students in Group I performed 6 of the procedures correctly, 50.0\% got 9 procedures 33.3\% performed 10 procedures correctly, with an average score of $9.2 \pm 0.72$ correct answers, whereas in Group II, 50\% of the students performed 9 procedures and $50.0 \%$ performed 10 procedures correctly, with an average score of $9.5 \pm 0.55$ correct answers. Statically, there was no significant differences between groups regarding the number of correct answers ( $p=0.423)$, but as for the subjective evolution about the multimedia program, $83.0 \%$ agreed that the program can be easily handled; $83.4 \%$ found the program nice to use; $50.0 \%$ agreed they had an immediate feedback; $100 \%$ declared the program educational and reassured their intention to have access to programs like that for other subjects. Finally, 50,0\% disagree that the program proved itself can replace the teacher. Conclusion: It was reckoned that the educational multimedia program proved itself effective in the learning of basic videosurgery techniques for the students in their second year of medical school but that the students agree that such programs are not enough to replace the teacher.
\end{abstract}

Key words: Education, medical; Educational technology; Education, distance; Medical illustration; Multimedia; Pneumoperitoneum, artificial; Laparoscopy.

\section{REFERÊNCIAS}

1. Andrade JCS. Nova metodologia para ensino e ensaio de técnicas operatórias em cirurgia cardíaca [Dissertação]. São Paulo(SP): Universidade Federal de São Paulo; 1994.

2. Azevedo JLMC, Guindalini RSC, Azevedo O, Paiva VC, Delorenzo A, Moreira MB. Avaliação do posicionamento da agulha de Veress durante o estabelecimento do pneumoperitônio pela técnica fechada, em porcos. Rev Col Bras Cir. 2004; 31(5):318-23.
3. Sigulem D. Um novo paradigma de aprendizado na prática médica da Escola Paulista de Medicina [Dissertação]. São Paulo (SP): Universidade Federal de São Paulo; 1997.

4- Markou SA, Koukouras D, Pimenidis T, Androulakis J. Using the hypertext software to develop computer-assisted instruction in oncology for medical students. J Cancer Educ. 1995; 10(3)1413.

5. Lindstrom RL. O incentivo da multimídia. In: Apresentações em multimídia. São Paulo: Makron Books; 1996. p. 1-24. 
6. Andrew SM, Benbow EW. Conversion of a traditional image archive into an image resource of compact disc. J Clin Pathol. 1997;50(7):544-7.

7. Carvalho PM, Sabbatini RME. Aplicações da multimídia na medicina. Rev Informéd. 1994; 1(3):15-9.

8. Mars M, McLean M. Student's perceptions of a multimedia computer-aided instruction resource in histology. S Afr Med J. 1996;86(6):1098-102.

9. Volpe RM, Sabbatini, RME. Aplicações da multimídia no ensino médico. Rev Informéd. 1994; 2(9):5-12.

10. Richardson D, Birge B. Teaching physiology by combined passive (pedagogical) and active (andragogical) methods. Am J Physiol. 1995; 268(6 Pt 3):S66-74.

11. Hindle T. A fase de preparação. In: Como fazer apresentações. São Paulo: Publifolha; 1999. p. 6-35.

12. Dick F, Leaven T,Dillman D, Torner R, Finken L. Core morphological concepts of disease for second-year medical students. Hum Pathol. 1998; 29(3):1017-20.

13. Lee W, Ault H, Kirk JS, Comstock CH. Interactive multimedia for prenatal ultrasound training. Obstet Gynecol. 1995; 85(1):135-40.

14. Hill DA. Role of the pre-test in the progressive assessment of medical students. Aust N Z J Surg.1992; 62(9):743-6.

15. Khandra MH, Guinea AI. Interactive urology: an evolution. Aust N Z J Surg. 1996; 66(5):478-80.

16. Teichmam JMH, Richards J. Multimedia to teach urology to medical students. Urology. 1999; 53(5):267-70.

17. Lamperti A, Sodicoff M. Computer-based neuroanatomy laboratory for medical students. Anat Rec. 1997; 249(4):422-8.

18. Rogers DA, Regehr G, Yeh KA, Howdieshell TR. Computerassisted learning versus a lecture and feedback seminar for teaching a basic surgical technical skill. Am J Surg. 1998; 175(6):508-10.
19. Franco G. An experimental study of a hypertext as an innovative teaching tool in learning about occupation risks. Med Lav. 1991;82(5):554-63.

20. Ringenberg QS, Johnson D, Doll DC, Anderson SP, Yarbro JW. Computer-assisted instruction in cancer for third-year medical students using the physician data query (PQD) system. J Cancer Educ. 1989; 4(1):11-5.

21. Lanna-Peixoto MA. The education of neurologists for the XXI century. Arq Neuropsiquiatr.1993;51(3):409-15.

22. Perfeito JAJ. Desenvolvimento e avaliação de um programa multimídia de computador para ensino de drenagem pleural [Dissertação]. São Paulo (SP): Universidade Federal de São Paulo; 2000.

23. Lévy P. As tecnologias da inteligência. São Paulo: Editora 34; 2000.

24. Seabra DDG. Desenvolvimento e validação de programa multimídia aplicado ao ensino do câncer de próstata [Dissertação]. São Paulo (SP): Universidade Federal de São Paulo; 2000.

Como citar este artigo:

Oliveira EFB, Azevedo JLMC, Azevedo OC. Eficácia de um simulador multimídia no ensino de técnicas básicas de videocirurgia para alunos do curso de graduação em medicina. Rev Col Bras Cir. 2007; 34(4). Disponível em URL: www.scielo.br/rcbc

Endereço para correspondência:

Eymard Francisco Brito de Oliveira

Av. Pres. Castelo Branco, 222

37062-690 - Varginha- MG

Tel: (35)3222-1424

E-mail: eymardfbo@hotmail.com

http://www.cardiovascular.med.br 